\title{
Mupirocin Ointment Prevents Early Post-Tympanostomy Tube Otorrhea: A Preliminary Study
}

\author{
Kye Hoon Park and Chi-Kyou Lee \\ Department of Otorhinolaryngology-Head \& Neck Surgery, Soonchunhyang University School of Medicine, Cheonan, Korea
}

Received November 14, 2012

Revised November 27, 2012

Accepted November 28, 2012

\author{
Address for correspondence \\ Chi-Kyou Lee, MD \\ Department of Otorhinolaryngology- \\ Head \& Neck Surgery, \\ Soonchunhyang University \\ Cheonan Hospital, \\ 31 Suncheonhyang 6-gil, Dongnam-gu, \\ Cheonan 330-721, Korea \\ Tel +82-41-570-3831 \\ Fax +82-41-579-9022 \\ E-mail_drqlee@hanmail.net
}

Background and Objectives: The most common complication of tympanostomy tube (T-tube) insertion is the development of postoperative otorrhea. Post-tympanostomy tube otorrhea (PTTO) is defined as active drainage through an existing T-tube. Many surgeons routinely use topical antibiotics as prophylaxis against early PTTO. Mupirocin calcium ointment is a topical antimicrobial agent with broad-spectrum antimicrobial activity against many Gram-positive organisms. This study evaluated the clinical effectiveness of topical mupirocin ointment in reducing early PTTO. Subjects and Methods: The study included 98 ears (67 patients, mean age 32.9 years) that had a T-tube inserted because of chronic middle ear effusion or atelectatic otitis media. A Paparella type-I polyethylene-tube coated with mupirocin was inserted through the tympanostomy. Patients were instructed not to use otic drops or any other medications. All patients were seen by day 14 postoperatively. Results: Early PTTO occurred in one case (1.5\%). No early PTTO was seen with a middle ear effusion. Nineteen children were treated under general anesthesia; none developed early PTTO. Conclusions: Insertion of a T-tube coated with mupirocin ointment could be effective at preventing early PTTO.

Korean J Audiol 2012;16:130-133

KEY WORDS: Mupirocin · Otorrhea · Tube insertion · Tympanostomy.

\section{Introduction}

Tympanostomy tube (T-tube) insertion is the most common procedure performed in children. The most common complication of T-tube insertion is the development of postoperative otorrhea, which typically has an incidence of $15-19 \%$, but can range from 3.4 to $74 \% .{ }^{1,2)}$ Post-tympanostomy tube otorrhea (PTTO) is defined as active drainage through an existing T-tube.

Based on a recent meta-analysis by Hochman, et al., ${ }^{2)}$ the following classification has been proposed to describe PTTO:

1) Early PTTO occurs less than 2 weeks postoperatively.

2) Late PTTO occurs more than 2 weeks postoperatively and is usually caused by pathologies similar to those responsible for acute otitis media or from external contamination.

3) Chronic PTTO refers to otorrhea of greater than 8 weeks duration.

4) Recurrent PTTO refers to distinct episodes with resolution in between.

Early PTTO seen at the first postoperative visit may be due to the operative procedure, underlying disease process, or both. Many otolaryngologists routinely use topical antibiotics as prophylaxis against early PTTO. Otic drops are frequently used for several days postoperatively for this purpose.

Mupirocin calcium ointment is a new topical antimicrobial agent that has broad-spectrum antimicrobial activity against many Gram-positive organisms, including methicillin- and vancomycin-resistant strains of Staphylococcus aureus (S. aureus). ${ }^{3)}$ It has a unique mechanism of action in which the drug binds to isoleucyl transfer RNA synthetase. ${ }^{4)}$ Mupirocin ointment is $97 \%$ effective at reducing $S$. aureus. ${ }^{4)}$

This study evaluated the clinical effectiveness of topical mupirocin ointment in reducing early PTTO.

\section{Subjects and Methods}

This study included 98 ears (67 patients; 36 males, 31 females; mean age 32.9 years) that had T-tubes inserted because of otitis media between October 2008 and November 2009 (Table 1). All patients undergoing T-tube insertion against 
Table 1. Results for patients undergoing tympanostomy tube insertion

\begin{tabular}{lcc}
\hline & No PTTO & Early PTTO \\
\hline Patients $(n=67)$ & 66 & 1 \\
Ears $(n=98)$ & 97 & 1 \\
Nature of fluid & & \\
$\quad$ None $(n=22)$ & 21 & 1 \\
Serous $(n=47)$ & 47 & 0 \\
Mucoid $(n=29)$ & 29 & 0 \\
Anesthesia & & \\
$\quad$ General $(n=19)$ & 19 & 0 \\
Local $(n=48)$ & 47 & 1 \\
\hline PTTO: Post-tympanostomy
\end{tabular}

PTTO: post-tympanostomy tube otorrhea

chronic middle ear effusion or atelectatic otitis media were included during this period. Informed consent was obtained from the patients or the families of children enrolled in the study.

Local or general anesthesia was selected case by case. As local anesthesia, xylocaine spray was primarily applied. In specific cases, infiltration anesthesia with a dental syringe was used. A consistent operating technique was applied in all patients, with the myringotomy performed in the anterior inferior quadrant and the effusion aspirated. When the tympanic membrane was retracted, the aerated space was incised. The type of middle-ear content was described as mucoid, serous, or none. A Paparella type-I polyethylene tube coated with mupirocin was inserted through the tympanostomy. Patients were instructed not to use otic drops or any other medications. All patients were seen by day 14 postoperatively, with a majority seen between days 7 and 14. The attending surgeon assessed early PTTO at the follow-up appointment.

\section{Results}

\section{Early PTTO}

Early PTTO occurred in one case (Table1). The patient developed otorrhea with otalgia at 1 week. The patient's external auditory canal was red and swollen. We gave a diagnosis of acute otitis externa. Oral antibiotics, analgesics, and otic drops were prescribed and no further symptoms persisted 3 days later.

\section{According to age}

Most commonly, T-tubes were inserted in patients younger than age 5 years. Atelectatic otitis media was most common between 10 and 40 years of age. After 40 years of age, middleear effusion (MEE) and atelectatic otitis media occurred equally (Fig. 1).

\section{According to middle ear contents}

Serous content was the most common finding, followed in

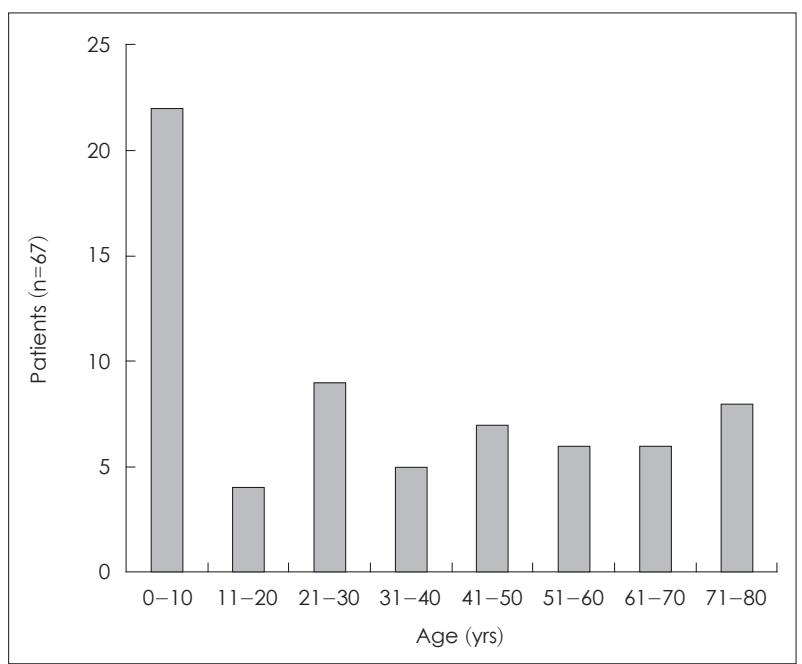

Fig. 1. Age distribution of the study group shows that tympanostomy tubes were inserted most frequently in children younger than 10 years old and distribution was even after this age.

order by mucoid, no fluid. Early PTTO developed in one patient with no fluid. No otorrhea occurred in patients with serous and mucoid content (Table 1).

\section{According to anesthesia}

Nineteen children were treated under general anesthesia; none developed early PTTO. Local anesthesia was used in the other patients. One case of early PTTO developed in patients treated under local anesthesia. Local injection was also used in this patient for additional pain control.

\section{Discussion}

Post-tympanostomy tube otorrhea is the most common complication of tympanostomy tube insertion. The cause of PTTO is still not clear. Gates, et al. ${ }^{1)}$ proposed a comprehensive list of extrinsic and intrinsic risk factors for PTTO. The extrinsic factors included tube type, ear canal sterilization, type of tympanostomy tube placed, perioperative antibiotic use, frequency of water contamination, environmental exposure to upper respiratory infections (i.e., in a daycare environment), and pacifier use. Intrinsic factors included patient age; type of effusion; prior treatment for acute otitis media; bacteriology of the MEE at the time of tympanostomy tube placement; the status of the middle-ear content at the time of the tympanostomy tube placement; status of the nose, adenoids, and paranasal sinuses; underlying environmental allergy; eustachian tube dysfunction; presence of nasopharyngeal reflux; and gastroesophageal reflux.

Many ways of preventing PTTO have been developed. Most methods control the extrinsic factors. Notably, Scott and Strunk ${ }^{5)}$ found that canal preparation with povidone iodine and $70 \%$ iso- 
propyl alcohol successfully sterilized only $33 \%$ of ears that contained bacteria and did not reduce the incidence of early PTTO. However, it did cause a $63 \%$ increase in operating time. Giebink, et al. ${ }^{6)}$ reported no significant difference in early PTTO, when either $70 \%$ alcohol or povidone iodine was used to prepare the external auditory canal. Furthermore, Kinsella, et al. ${ }^{7)}$ suggested that it is reasonable to assume that early PTTO is determined more by the preexisting condition of the middle ear than by external contamination at the time of surgery, because no difference in PTTO rates were observed when comparing touch and no-touch techniques.

A more frequently used method for prophylaxis against early PTTO is the use of ototopical drops at the time of surgery. One study attempted to distinguish between the chemical effects of the prophylactic antibiotic drops versus the mechanical effects of normal saline instillation and found that PTTO rates were lower in the antibiotic group. ${ }^{8)}$ However, Gross, et al. ${ }^{9}$ looked at early PTTO rates in a prospective, blinded, controlled trial comparing saline irrigation of the middle-ear space at the time of tympanostomy tube placement versus the use of otic drops postoperatively for 3 days. They found that the rate and degree of drainage were both reduced statistically in the saline irrigation group, which is in contrast to the findings mentioned above.

A meta-analysis of 9 randomized studies suggested that prophylaxis using topical antibiotic drops may reduce the incidence of PTTO by half. ${ }^{2)}$

In a recent study conducted in our country, Korea, the common pathogens of PTTO were coagulase-negative Staphylococcus, Pseudomonas, and methicillin-resistant $S$. aureus (MRSA) ${ }^{10)}$ It is very difficult to treat MRSA otorrhea, which tends to worsen rapidly. Furukawa, et al. ${ }^{3)}$ used mupirocin ointment and ofloxacin otic ear drops to treat MRSA otorrhea in chronic otitis media and reported complete control of the otorrhea in the mupirocin group without ototoxicity, but not in the ofloxacin otic drop group. Therefore, we used mupirocin ointment $\left(\right.$ Bactroban $\left.^{\circledR}\right)$.

One of our patients $(1.5 \%)$ developed early PTTO. No early PTTO was seen in middle ear effusion. This patient had a problem during the procedure; the skin of the external auditory canal was damaged during anesthesia. Acute external otitis developed 1 week later and was treated with oral antibiotics and analgesics; no further symptoms were observed 3 days later.

Debruyne, et al. ${ }^{11)}$ found a greater incidence of early PTTO in children younger than 2 years of age, with an incidence of $20 \%$ in this age group compared to a $7.5 \%$ incidence of early PTTO in children older than 6 years. None of our patients younger than 2 years of age developed early PTTO and our data show- ed no age-related differences.

Many studies have established that PTTO rates are higher in children with mucoid or purulent MEEs at the time of tympanostomy tube placement as opposed to dry ears or those with serous effusion. ${ }^{12)}$ However, no difference related to mucoid or serous effusion was seen in our study.

Our data suggest that early PTTO is a postoperative wound complication. Chronic MEE and retracted otitis media are not the result of infection, but are infection-prone states. Therefore, we postulate that early PTTO is the result of a wound complication induced by the tube insertion procedure. The most effective method to prevent wound complications is to maintain a clean wound and through postoperative wound care. However, a clean wound is practically impossible in middleear surgery. Therefore, effective postoperative management, dressings, and local antibiotics, are important. If needed, systemic antibiotics can be used. Golz, et al. ${ }^{13)}$ retrospectively investigated the use of postoperative systemic antibiotic prophylaxis and found some statistically significant differences. They followed this with a prospective study investigating a one-time preoperative prophylactic dose of Augmentin (GlaxoSmithKline Beecham, Philadelphia, PA, USA) and found a significant reduction in early PTTO.

If the probability of early PTTO developing is high, as in acute otitis media, purulent discharge, or a traumatic procedure, then more frequent aural cleaning should be performed and systemic and local antibiotics should be used. Mupirocin ointment appears to be effective for controlling local infection.

\section{Conclusion}

Early PTTO is the most common postoperative complication of T-tube insertion. To prevent this complication, local infection has to be controlled. Our data suggested that coating the T-tube with mupirocin ointment could be effective for preventing early PTTO.

\section{REFERENCES}

1) Gates GA, Avery C, Prihoda TJ, Holt GR. Post-tympanostomy otorrhea. Laryngoscope 1986;96:630-4.

2) Hochman J, Blakley B, Abdoh A, Aleid H. Post-tympanostomy tube otorrhea: a meta-analysis. Otolaryngol Head Neck Surg 2006;135:811.

3) Furukawa M, Minekawa A, Haruyama T, Narui Y, Sugita G, Sugita $\mathrm{R}$, et al. Clinical effectiveness of ototopical application of mupirocin ointment in methicillin-resistant Staphylococcus aureus otorrhea. Otol Neurotol 2008;29:676-8.

4) Henkel T, Finlay J. Emergence of resistance during mupirocin treatment: is it a problem in clinical practice? J Chemother 1999;11:331-7.

5) Scott BA, Strunk CL Jr. Posttympanostomy otorrhea: the efficacy of canal preparation. Laryngoscope 1992;102:1103-7.

6) Giebink GS, Daly K, Buran DJ, Satz M, Ayre T. Predictors for post- 
operative otorrhea following tympanostomy tube insertion. Arch Otolaryngol Head Neck Surg 1992;118:491-4.

7) Kinsella JB, Fenton J, Donnelly MJ, McShane DP. Tympanostomy tubes and early post-operative otorrhea. Int J Pediatr Otorhinolaryngol 1994;30:111-4.

8) Shinkwin CA, Murty GE, Simo R, Jones NS. Per-operative antibiotic/steroid prophylaxis of tympanostomy tube otorrhoea: chemical or mechanical effect? J Laryngol Otol 1996;110:531-3.

9) Gross RD, Burgess LP, Holtel MR, Hall DJ, Ramsey M, Tsai PD, et al. Saline irrigation in the prevention of otorrhea after tympanostomy tube placement. Laryngoscope 2000;110(2 Pt 1):246-9.

10) Jung H, Lee SK, Cha SH, Byun JY, Park MS, Yeo SG. Current bac- teriology of chronic otitis media with effusion: high rate of nosocomial infection and decreased antibiotic sensitivity. J Infect 2009;59: 308-16.

11) Debruyne F, Jorissen M, Poelmans J. Otorrhea during transtympanal ventilation. Am J Otol 1988;9:316-7.

12) Balkany TJ, Barkin RM, Suzuki BH, Watson WJ. A prospective study of infection following tympanostomy and tube insertion. Am J Otol 1983;4:288-91.

13) Golz A, Ghersin T, Joachims HZ, Westerman ST, Gilbert LM, Netzer A. Prophylactic treatment after ventilation tube insertion: comparison of various methods. Otolaryngol Head Neck Surg 1998;119:11720. 